\title{
O PSICÓLOGO NO SERVIÇO DE ACOLHIMENTO INSTITUCIONAL A CRIANÇAS E ADOLESCENTES: SOBRE QUESTÕES E POSSIBILIDADES
}

\author{
Sthefânia Carvalho
}

\section{“CAUSO" 1: NA ROTINA DO INESPERADO}

"A noite havia caído e, com ela, era chegada minha hora de ir embora. Já ia me despedindo das crianças, quando comecei a escutar a voz de Francielle gritando pela casa. Aquela voz que, em momentos de certa calmaria, era doce, suave e recheava lindos cantos, em momentos de transbordamento de angústia se transformava em um urro grotesco que arrepiava a espinha até do mais valentão. Batia nos móveis, socava as paredes, xingava, ameaçava todos a seu redor e gritava que não queria mais ficar naquele inferno. Em um piscar de olhos, estava em cima do telhado, anunciando que iria se jogar. As outras crianças se amontoavam em um canto do quintal, em um misto de medo e excitação.

Rapidamente fiz alguns cálculos: ela iria mesmo se jogar? Ou estava blefando? Eu subiria para tentar conversar com ela? Caso subisse, ajudaria a amenizar ou, tiro pela culatra, a intensificar a situação? Chamaria a ambulância? Não dava tempo, além de quê, mesmo que chegassem, o que eles poderiam conseguir além daquilo que nós mesmos poderíamos?

Subi.

O educador cuidava de levar os demais para dentro da casa.

Ao me ver no telhado ela se assustou, talvez pensando que eu fosse tentar segurá-la. Senteime a certa distância e fiquei quieta olhando para ela. Eu sentia medo e não sabia muito bem o que fazer.

- "O que você veio fazer aqui?"

- "Vim te fazer companhia".

Após um longo tempo em que ambas ficamos em silêncio, comecei a contar para ela histórias de sua vida, retomando sua trajetória até o presente momento. Ela me mirava atenta e, com os olhos, pedia que eu continuasse. Cheguei a um ponto em que pensava 'e agora? E agora?!'... E ela, com sua expressão, me interrogava a mesma questão. Pedi então que ela esperasse mais um pouquinho antes de pular, pois eu gostaria de Ihe mostrar algo. Desci do telhado, peguei na biblioteca da casa um livro de Drummond, voltei lá pra cima e perguntei se poderia ler algo para ela. Li o poema 'José'. Sorriu, me perguntou se ela era o José. Eu disse que somente ela poderia dizer quem ela era, dei boa noite, pois, afinal, já fazia muito frio para ficar lá em cima, e desci. Ela desceu atrás de mim, me disse que estava com muito sono e foi dormir". 


\section{ACOLHIMENTO INSTITUCIONAL}

Antes de mergulharmos na discussão deste texto, uma breve contextualização se faz necessária a fim de situar os mais diversos leitores sobre o campo ao qual nos referimos.

acolhimento institucional é uma medida protetiva de caráter provisório e excepcional para crianças e adolescentes cujas famílias ou responsáveis estão temporariamente impossibilitados de cumprir sua função de cuidado e proteção, implicando na violação de direitos da criança ou adolescente em questão. Esta medida deve ser aplicada apenas quando esgotados todos os recursos para a manutenção da criança junto à família de origem, família extensa ou outros vínculos comunitários. A situação de pobreza familiar não constitui motivo suficiente para o afastamento da criança e do adolescente de seu convívio e, neste caso, o Estado deve garantir à família a possibilidade de que tenha condições materiais mínimas para retomar o cuidado de seus filhos, e não encaminhá-los para o Serviço de Acolhimento. Estar em situação de acolhimento institucional não representa privação de liberdade e, inclusive, deve-se preservar o direito da criança à convivência familiar e comunitária, além de trabalhar a possibilidade de seu retorno à família de origem ou colocação em família substituta (Brasil, 1990; Brasil, 2006a; Brasil, 2009).

Os Serviços de Acolhimento Institucional para Crianças e Adolescentes (Saica)' representam uma das possibilidades de execução dessa medida protetiva, sendo moradias com aspecto residencial para até 20 crianças e adolescentes que contam com coordenação, equipe técnica, educadores e equipe operacional, responsáveis pelo atendimento aos meninos e suas famílias (Brasil, 1990; Brasil, 2009).

\section{O PSICÓlOGO NO SAICA: DA LEGISLAÇÃO AO COTIDIANO}

De acordo com a Norma Operacional Básica de Recursos Humanos do Sistema Único de Assistência Social (NOB-RH SUAS) (Brasil, 2006b), ratificada em 20II pela Resolução número 17 do Conselho Nacional de Assistência Social (CNAS) (Brasil, 20 I I), a participação do psicólogo passa a ser obrigatória na equipe de referência dos serviços socioassistenciais do SUAS, entre os quais estão os Saicas.

Isto significa que em todos os Serviços de Acolhimento Institucional do país deve haver um psicólogo compondo a equipe de trabalho, o que faz com que seja um expressivo campo de atuação para estes profissionais. Disso decorre a constante necessidade de discussões e construções de referenciais éticos, teóricos e metodológicos a respeito da prática psi nessa área, necessidade que remete diretamente à formação dos profissionais.

As Orientações Técnicas para os Serviços de Acolhimento (Brasil, 2009) retomam proposições do Estatuto da Criança e do Adolescente (Brasil, 1990) e da Política Nacional de Assistência Social (Brasil, 2005) e apresentam as atividades desenvolvidas pela equipe técnica, além de diretrizes gerais para sua realização. Como exemplo, podemos citar

I O Saica representa uma reformulação técnica, conceitual e operacional do que anteriormente era o Abrigo, maneira como este serviço ainda é conhecido por alguns profissionais e usuários. 
o acompanhamento psicossocial dos acolhidos e suas famílias com vistas à reintegração familiar, o apoio na seleção e formação dos educadores e a articulação com o Sistema de Garantia de Direitos (SGD).

É importante destacar que neste documento não existe uma diferenciação entre as atividades atribuídas a psicólogos e assistentes sociais, sendo todas consideradas atividades referentes à equipe técnica.

Apesar de os textos reguladores e orientadores das políticas socioassistenciais para a infância terem sido modificados e avançado bastante nos últimos anos, as práticas nos serviços não acompanharam este movimento, o que tem relação direta com o processo sócio-histórico de desenvolvimento da assistência à infância no Brasil - marcado pela benemerência, assistencialismo, com forte influência das igrejas, voltado ao controle social das camadas mais pobres em uma perspectiva moralizante e ideológica de educação dos pobres etc. (Rizzini, 2008; Rizzini e Pilotti, 201 I).

Entendemos que as revisões da legislação e de normativas são muito importantes, mas não garantem as mudanças propostas por estes mesmos textos. Apesar das inegáveis conquistas concretas alcançadas, ainda há muitas disputas a serem enfrentadas no sentido de uma mudança de culturas e práticas institucionais para que estejam aliadas a tais propostas de transformação.

Para além das legislações, normativas e recomendações oficiais que garantem certa estrutura e condições sobre as quais a política pública se desenvolverá, existe a dimensão das práticas que se constituirão a partir da ação dos trabalhadores e das construções e relações que puderem criar entre si, com os usuários e com os quase infinitos elementos que compõem qualquer campo. Neste sentido, o "como" não está predefinido e aí está o espaço de movimentação para que se ocupe este lugar de variadas formas, sempre a partir de uma posição ético-política.

Compartilhamos da concepção de que 'o que existe hoje poderia não ser mais o que é', ou seja, que toda realidade, sempre sócio-histórica, é um jogo de forças permanente que porta um caráter de variação e de transitoriedade, de inacabamento e de gestação constante. Que nos faz, portanto, diferir de nós mesmos [...]. Se há uma perspectiva ideal, trata-se daquela que entende que não existem duas instituições semelhantes e que uma mesma instituição não deveria cessar de se transformar o tempo todo (Vicentin, 2016, p.29).

Neste trabalho, apresentaremos compreensões que não delimitam um papel definitivo para a atuação do psicólogo no Saica, mas colaboram com alguns traços no desenho de uma ética que sustente este trabalho. Ética esta comprometida com a garantia dos direitos sociais, a erradicação da desigualdade sócio-étnico-econômica, a não massificação dos sujeitos, não institucionalização, com o espaço para a singularidade e para o desejo e com a quebra do ciclo de repetições transgeracionais de violações e violências. Um posicionamento político que pretende colaborar para a construção de um fazer neste campo. 
Este texto é composto por discussões pertinentes à área, questões recorrentes na prática e alguns conceitos, entrelaçados e permeados por fragmentos de experiências institucionais de diversos psicólogos em Saica².

Apresentaremos algumas cenas-chave dessa montagem institucional e algumas pistas para a atuação do psicólogo neste contexto, propondo uma interlocução com os profissionais, pesquisadores e interessados, desejando ser mais uma voz a compor a permanente construção (e disputa) do campo em questão.

A multiplicidade das tarefas que um psicólogo pode desempenhar em um Saica faz com que se interrogue a legitimidade e a especificidade do trabalho, delineando as seguintes questões: o que caracteriza o trabalho de um psicólogo? O que autoriza um psicólogo a nomear-se enquanto tal? E, ainda, a que referencial técnico e conceitual cada um se remete quando fala em Psicologia?

○ cotidiano do psicólogo nos serviços de acolhimento institucional e em muitos outros contextos de atuação institucional é diferente do setting tradicionalmente associado ao fazer clínico em psicologia. Não tem sala, não atende com hora marcada e raramente atua sozinho na relação um a um que configura os atendimentos individuais. Para além da fala e do discurso, intervém em ato, a partir das ações e situações. Seu foco de trabaIho não é apenas cada um dos indivíduos, mas um olhar para a instituição como um todo e as práticas a ela entrelaçadas, considerando cada criança e também as relações entre elas, suas famílias, os demais profissionais, a organização e proposta do trabalho na instituição e a articulação com a rede intersetorial (fórum, escolas, saúde e lazer). Seu material de trabalho é quase tudo que se passa nos diversos setores da vida de crianças e adolescentes.

Retomando anotações do diário de campo que traz os registros da atuação de uma psicóloga em um Saica, encontramos a seguinte descrição de um dia de trabalho:

Naquele dia, fui a uma reunião de escola junto com a mãe de uma criança, depois joguei bola na praça com as adolescentes e, no caminho de volta, conversamos sobre paixões e desilusões. Junto com um educador, separei uma briga e mediei uma conversa entre dois meninos na casa, depois consertamos o jogo de futebol de botão, jantei com eles, contei uma história para os pequenos e fui embora.

Há uma intensa potência neste trabalho, justamente por sua abrangência, já que é composto por diversos momentos do cotidiano institucional, e pela possibilidade de acompanhar presencialmente inúmeras esferas da vida da criança - o que possibilita um campo de intervenção em ato, a partir do que se vive e das relações que se estabelecem.

2 Os trechos em que são relatadas experiências de trabalho dos psicólogos em SAICA estarão destacados em itálico para diferenciá-los dos demais trechos, facilitando, assim, a compreensão do texto. 
Neste contexto tão dinâmico, a disponibilidade para estar em relação nas mais diversas e irreverentes situações é condição para uma atuação que gere efeitos interessantes. Em contrapartida, a incansável busca do psicólogo por delimitar sua identidade profissional pode engessar a criatividade e a ousadia necessárias a essa empreitada.

Em certa ocasião, uma colega, após breve hesitação, saiu correndo pela rua atrás de um adolescente que havia fugido muito bravo e triste. Encontrou-o em uma praça, ele permitiu que ela ficasse ao seu lado, em silêncio, por muito tempo. Depois trocaram algumas poucas palavras e retornaram, horas mais tarde. Os profissionais do serviço ficaram surpresos com o retorno do adolescente. Aquela atitude foi muito marcante na história daquela instituição e na maneira como compreendiam e lidavam com as "fugas" dos adolescentes. Depois desse episódio inaugural, houve diversas situações em que técnicos e educadores foram procurar adolescentes escapulidos. Encontraram alguns, outros não. Muitos voltaram, alguns, não. Escolhas. A dos meninos de voltar ou não e a dos adultos, de procurá-los ou de enviar ao Fórum um comunicado de evasão.

Uma vez garantido o desprendimento de um enquadre específico, o psicólogo contribui na composição deste trabalho ao considerar a singularidade em sua escuta e análise sobre os processos. Ao salientar a singularidade, referimo-nos à singularidade do outro (no caso, o jovem), de si e daquilo que se produz no encontro entre ambos. Na cena da saída não autorizada, assim como na cena do telhado apresentada no início do texto, a singularidade remete ao reconhecimento de um percurso e também à construção (em ato) de uma história, que se dá no entre, sendo tecida nas próprias relações, a partir do que afirmamos que há um viver com que é fundamental para essa tessitura. A partir disso, podemos defender o viver com como uma estratégia de trabalho.

\section{QUE CASA É ESSA? - UM CAMPO DE MISTURAS}

Com relação à produção subjetiva, partimos da concepção da multiplicidade, considerando que sua produção não é exclusivamente individual, nem apenas coletiva ou institucional, mas que se engendra para além do indivíduo, construindo-se coletiva e coextensivamente à produção do campo social em um determinado contexto histórico (Guattari, 1992).

Consideramos, portanto, que as práticas em uma instituição influenciam diretamente a produção de subjetividades naquele espaço-tempo. Neste sentido, as escolhas feitas para a constituição daquele ambiente têm efeitos diretos sobre os discursos que circulam e, consequentemente, sobre as crianças e adolescentes. As crianças podem servir sua própria comida? Que princípios norteiam a construção das regras de convivência? Quais portas ficam trancadas e quais ficam abertas? Com que frequência os familiares são convidados a estar no abrigo e participar das ações referentes a seus filhos? Qual é a aparência desta casa? Ela de fato se parece com uma casa? Ela é aconchegante? Existem espaços e permissão para que atividades diversificadas aconteçam simultaneamente ou todos precisam estar ao mesmo tempo no mesmo espaço, sempre juntos, fazendo a mesma coisa 
(todos na sala assistindo televisão, por exemplo)? Os moradores podem receber amigos em casa? Há marcas dos meninos e meninas pelas paredes? Quem pode circular por esta casa? Como é a relação da instituição com voluntários e qual limite para o acesso que têm sobre as crianças?

A partir das respostas a estas e outras inúmeras perguntas, desenham-se cenários, possibilidades e efeitos de subjetivação significativamente diferentes entre si.

Neste sentido, o discurso é entendido como um dispositivo organizador da realidade. Para além de uma relação entre palavra e coisa, constitui-se como um conjunto de regras que, em ato, põe em funcionamento enunciados e relações (Foucault, 2009).

A fim de dar corpo ao que afirmamos, vamos passear por uma cena emblemática dos Serviços de acolhimento de crianças e adolescentes. Muitos daqueles que já entraram em instituições como esta provavelmente terão vivido a experiência de serem abordados por crianças ou adolescentes com pedidos como mexer em seu celular, dinheiro para comprar algo, presentes, passeios e inclusive o pedido para que seja padrinho deles ou que os adote. Somado a isso, um contato físico apressado: abraços, colo, mãos dadas, toques nos cabelos. Será que estas crianças, em outro contexto, teriam o mesmo comportamento? Certamente, não. A maneira como os atores institucionais lidam com a perspectiva de adoção, as histórias da família de origem, o que significa estar no abrigo e as possibilidades colocadas para as crianças, as coloca em lugares discursivos específicos na relação com o outro, e elas criarão respostas a partir deste lugar destinado a elas pela montagem institucional. Na situação mencionada, as crianças respondem do lugar de quem está em falta em relação ao outro que é, assim, pleno. Lugar de quem não tem, de quem precisa do outro que, mesmo desconhecido, representa uma "salvação" de sua condição atual. Podemos reconhecer na situação relatada efeitos do oficialmente ultrapassado, mas ainda operante, discurso sobre a "criança carente".

Por outro lado, certamente alguns de nós já pudemos também testemunhar instituições de acolhimento em que as crianças não nos interpelam com pedidos sem fim, nem deixam de fazer aquilo em que estão envolvidas para poderem simplesmente desfrutar de nossa presença ou ousam até, vejam só, lançar um olhar desconfiado como quem perguntasse "o que é que você quer de mim? O que está fazendo aqui?".

Como contribuição a essa discussão, do ponto de vista da psicanálise, podemos afirmar:

É $\bigcirc$ Outro ${ }^{3}$ que dá à criança o sentimento de que ela tem um lugar. [...] $\bigcirc$ lugar que as pessoas autorizam ou não a criança ocupar, a função que a gente lhe dá sem que saiba, como doente, por exemplo, para abrandar a angústia, são elementos de um jogo que existe na família como também em toda instituição da qual ela

3 Termo cunhado por Jacques Lacan, utilizado em psicanálise para designar um lugar simbólico que determina o sujeito, inserindo-o na linguagem (Roudinesco \& Plon, 1998). 
participa. $\bigcirc$ sentimento que a criança ou o jovem tem de seu lugar no mundo é igualmente ligado à maneira na qual ele tem contado, sido importante ou não, para alguém, sem ter de se apagar como sujeito (Altoé, 2010, p.62).

Destacando questões pertinentes ao trabalho no Saica, vale indicar algumas de suas características peculiares, que marcam profundamente tanto seu funcionamento quanto as práticas que ali ocorrem. $\bigcirc$ abrigo não para, não fecha. Lá, não se encerra o expediente. Funciona vinte e quatro horas por dia, manhã, tarde, noite, madrugada, sete dias por semana, inclusive (e principalmente) nos feriados. Os acontecimentos, obviamente, não têm hora marcada. A vida está acontecendo, em sua expressão dinâmica e inapreensível.

Outra característica fundante é que a instituição está temporariamente cumprindo a função de cuidar de crianças e adolescentes, de forma compartilhada com a família sempre que possível. Esse cuidado não se refere apenas à responsabilidade legal e cuidados básicos, de sobrevivência das vinte crianças e adolescentes, mas, sobretudo, a um redemoinho de afetos atualizados nessas relações, convocando os profissionais a uma posição muito delicada na relação com as crianças e suas famílias de origem. Muitas vezes, cumprir temporariamente e de forma compartilhada a função de família tende a se misturar com ocupar o lugar da família na vida da criança, captura que opera sobre as crianças, as famílias e também sobre os profissionais do Serviço de Acolhimento.

São inúmeras as situações que exemplificam a montagem referida acima. $\bigcirc$ fato de as crianças e adolescentes chamarem os funcionários pelos referenciais familiares de tio e tia, se referirem ao coordenador ou outra figura na instituição como mãe ou pai, por vezes, incentivados pelos próprios adultos a procederem desta forma, nos permite analisar no discurso essa confusão de papéis.

As experiências são frutos de muitas misturas. É comum crianças passarem o final de semana ou alguma data comemorativa, como o Natal, na casa de educadores, participando de sua rotina familiar, íntima. Familiares das crianças, por vezes, relatam sentir-se constrangidos nas visitas aos filhos acolhidos, percebendo-se avaliados em sua conduta pela equipe e desprezados pelos filhos, em uma cobrança implícita de que pudessem garantir as condições providas pela instituição, como, por exemplo, cinco refeições diárias, passeios caros e diversos presentes. Os profissionais ficam extremamente mobilizados com o sofrimento das crianças e é comum que, como reação, façam um julgamento moral das atitudes de suas famílias e culpabilizem as mesmas pela situação em que se encontram, tendo, como consequência, dificuldade em acolhê-las e em desenvolver um trabalho com elas.

Com relação aos bebês e crianças pequenas, é frequente encontrar tensões entre profissionais e familiares quando os últimos se aproximam de seus filhos, uma vez que os profissionais (incluindo o psicólogo) podem temer que a família não seja capaz de cuidar daquele ser frágil que agora está sob seus cuidados. Por outro lado, não é raro que evitem estabelecer um vínculo com as crianças e adolescentes na tentativa de proteger-se do sofrimento gerado pela posterior separação daqueles sobre quem derramaram 
seus cuidados. $\bigcirc$ discurso sobre a adoção também perpassa essas relações, não sendo incomum o pedido das crianças para que sejam adotadas pelos profissionais e, também, o caminho inverso - profissionais que desejam e pleiteiam adotar uma criança que os mobiliza especialmente.

Nesse contexto, constituem-se rivalidades entre familiares e profissionais quando esses disputam quem cuida melhor, tem mais condições, toma as decisões, ou até de quem a criança gosta mais. Disputam, como em uma final de "dança das cadeiras", ocupar exatamente o mesmo lugar que a família na relação com a criança.

Nas situações que elencamos, pretendemos ilustrar o entrelaçamento entre o campo profissional e o pessoal inerente a este contexto ${ }^{4}$. Ao apresentar estes elementos, reconhecemos que eles existem e assumimos que uma importante parcela dos afetos circulantes passa inevitavelmente por aí, o que tem efeitos diretos nas práticas e nos modos de cuidado que se desenvolvem nestas instituições. Mesmo quando não chegam a ser concretamente atuados, afetos similares são pensados, sentidos, sofridos e sonhados.

A relação dos profissionais do Saica com as crianças não é uma relação familiar. Ao mesmo tempo, é difícil posicionar-se em outro lugar, dada a convocação que esta montagem institucional produz: estar em uma relação tão próxima com crianças afastadas do convívio familiar cotidiano. $\bigcirc$ desafio é construir outro lugar na relação com as crianças e também com suas famílias, um lugar que não pretende substituir a família, para que possamos desempenhar nossa função de proteção e garantia de direitos podendo, inclusive, trabalhar sobre as relações das crianças acolhidas com suas familias e suas histórias.

As relações estabelecidas pelas familias, pelas crianças e pelos adolescentes com todos aqueles que são agentes da proteção social têm a possibilidade de serem mediações potencializadoras, mas, para isso, as familias precisam ser acolhidas como agentes de transformação e apoiadas em seus movimentos de mudança e compreendidas em seus próprios contextos. Isso significa considerar que as famílias são plurais, diversas em sua organização e em seus modos de convivência (Moreira, Bedran, Carellos e Passos, 2013, p.66).

A tarefa é árdua e o psicólogo, ao ter o desejo de sustentar a construção deste outro lugar - não familiar - na relação com a criança, contribui com os processos de diferenciação e a construção de outros modos de a equipe se relacionar com os meninos e meninas e suas famílias.

Quando trabalhamos com crianças e adolescentes de forma geral e, especialmente, em instituições de moradia, como são os Saicas, o campo da educação está subjacente, permeando qualquer outra prática, inclusive a prática psi. A criança não faz uma distinção funcional entre os adultos que compõem sua rede de relações, separando-os por áreas de

4 Sabemos das limitações e da artificialidade da distinção entre "campo profissional" e "campo pessoal". Contudo, optamos por utilizar este recurso como uma estratégia didática para expressar com mais clareza a noção pretendida. 
atuação. No limite, somos adultos assumindo posicionamentos, fazendo escolhas, atribuindo sentido ao mundo e às relações, mostrando possibilidades de experienciar situações e isso irá compor a história de construção daqueles sujeitos, inferindo-lhes marcas referenciais.

$\bigcirc$ aspecto educativo e a teia de afetos que circulam pela instituição são pontos centrais e complexos no manejo desse trabalho. A relação entre adultos e crianças é pautada pelos valores, crenças, visão de mundo, concepções e histórias de vida de cada profissional. No Saica, a dimensão pessoal atualiza-se, e os profissionais tendem a atuar de acordo com repertórios próprios, recorrendo à sua história de vida e aos saberes ao longo dela construídos como referenciais para ensejar diferentes ensinamentos, broncas, negociações, prazeres, castigos, brigas, brincadeiras, portas trancadas, maneiras de lidar com o sofrimento, alimentação, proibições, amores, permissões, julgamentos e privilégios.

Nesse sentido, o psicólogo contribui quando, atento para esses movimentos, convida à fala, ao compartilhamento, à elaboração e à construção coletiva desse mosaico de composições, colaborando para a criação de uma ação que não seja pautada apenas em respostas espontâneas, pressupostos individuais e na repetição das histórias ou modelos de cada profissional. Esse movimento pode ser produzido e alimentado de diversas formas: reuniões periódicas entre profissionais do serviço, registro escrito sistemático de situações de trabalho, priorização das ações em duplas, compartilhamento de informações importantes sobre a história da criança com os educadores, formação continuada, supervisão institucional e diversas outras que se possa inventar.

Afirmar processos de diferenciação exige estratégias institucionais, sem as quais experimentamos imensa dificuldade em construir uma mesma direção política que oriente o trabalho, o que nos faz reféns das arbitrariedades individuais ou busca por uniformização das condutas dos profissionais em questão.

Sem essa direção de trabalho, as crianças ficam à mercê de balizas divergentes entre si, a depender da decisão arbitrária do adulto presente em cada cena, o que é uma vivência extremamente angustiante e psiquicamente desorganizadora. É necessário que as crianças e adolescentes tenham confiança em um ambiente relativamente estável, ancorado em referenciais simbólicos gerais, o que não as deixa como objetos do exercício de poder de cada um dos adultos.

Defendemos que a direção geral esteja contemplada no Projeto Político Pedagógico da instituição, que de nada serve quando é apenas uma formalidade, mas pode ser um norteador importantíssimo uma vez que prevê intencionalidade e direcionamento político e ético nas práticas realizadas pela equipe do Saica.

Acompanhemos, a seguir, uma cena que dialoga com as questões apresentadas. 


\section{"CAUSO" 2: A VIDA NA INSTITUIÇÃO E A INSTITUIÇÃO NA VIDA}

"Na República Jovem5, Serviço do SUAS destinado a jovens que completam dezoito anos e não têm a possibilidade do retorno à família de origem e nem encaminhamento a uma moradia autônoma, conheci Luka.

Chegaram junto com ele uma poupança de dois mil reais, uma indicação de que era 'um menino que não dava problemas', um relatório de apenas três páginas sobre seus últimos dezessete anos vividos na mesma instituição e um olhar vazio.

Na primeira noite em que passou na casa, mal conseguia conversar conosco, parecia anestesiado, em um estado de paralisia. Naquela ocasião, os outros moradores da República passariam a noite fora e ele seria o único a dormir na casa. Deixava escapar apenas um tímido e disfarçado pedido de que ficássemos ali. "Nunca fiquei sozinho". "Mas... nunca, nunca?". "Não, nem por um minuto". Ficamos até às 22h. Garantimos que voltaríamos cedo no dia seguinte.

No outro dia, percebemos que ele não havia comido nada, apesar da dispensa cheia de alternativas. "Não sei cozinhar nada. Nem sei acender o fogão".

Gastou os dois mil reais que o abrigo havia guardado de seu salário sem deixar que ele tivesse acesso em menos de um mês, sem nem saber com o quê. Como não tinha acesso ao dinheiro no período do abrigo, não desfrutou da recompensa por seu trabalho e nem aprendeu o valor das coisas, nem a cuidar do dinheiro.

Nessas duas situações, com relação à comida e ao dinheiro, percebemos evidentes traços de uma formação que desconsiderou a importância desses aprendizados, e, poderíamos supor, de quaisquer recursos para tocar a vida fora do abrigo.

Com o tempo, foi-se deixando conhecer. Contou-nos que não sabia absolutamente nada sobre sua origem. Nenhum nome, nenhuma história, nenhuma justificativa. Havia sido adotado por uma educadora do abrigo em que morava quando tinha seis anos, mas, foi "devolvido" ao mesmo abrigo dois anos depois, sem entender o porquê. Seguiu, então, morando neste abrigo até que a mesma educadora, que continuava trabalhando lá, novamente pleiteia sua adoção. Ele fica com ela por mais um tempo e, mais uma vez, repete-se a história da devolução. Luka nos conta que sua interpretação é de que ele "não sabe como ser um bom filho", e, por isso, nem sua mãe, nem a educadora quiseram ficar com ele. No momento de sua saída do abrigo, essa mesma pessoa, que já não trabalhava mais no abrigo, oferece um dos quartos de sua casa para que ele alugue. Ele fica muito em dúvida, pois, nesse momento crítico e assustador de saída do abrigo, essa era uma tentadora possibilidade de viver algo já conhecido e que representava para ele uma referência familiar. Finalmente poderia ter uma família, mesmo que houvesse um preço a ser pago: além do aluguel, o assujeitamento ao lugar daquele que não sabe ser um bom filho e, por isso, deve aceitar qualquer migalha, qualquer violência, qualquer contrato.

Luka aceitou nosso convite de ficar um tempo na República até que pudesse avaliar qual seria um caminho interessante para ele.

5 Serviço de acolhimento com capacidade de atendimento para seis jovens entre 18 e 21 anos, contando com um coordenador, um assistente social e um psicólogo para até quatro casas. 
Certa vez, batendo papo com os adolescentes, falávamos sobre origem, traços físicos e descendência. Luka ficou silencioso e atento. Ao final da conversa, disse que não sabia nada sobre sua história. Perguntamos se sabia o que constava nos relatórios que o abrigo enviava ao Fórum. Ele imediatamente respondeu que as crianças não podem ver os relatórios, que é coisa para os adultos e, por isso, nunca tinha tido acesso a nenhum relatório ou outra forma de registro sobre sua história.

Diante disso, propusemos a Luka uma ida ao fórum, acompanhado por um de nós, para que visse seu processo e tivesse acesso a informações sobre sua família, seu acolhimento, sua infância. Esta possibilidade de movimentar o que estava tamponado há anos causou uma ansiedade para todos nós. Para Luka, era dificil mexer em algo que ao longo de toda sua vida havia sido mantido abafado pelos agentes institucionais, possivelmente como uma tentativa de poupá-lo de situações difíceis - ação que, ao invés de protegê-lo, talvez o tenha deixado sem o solo a partir do qual desenvolver suas raízes, sua identidade, tornou-se o "menino que não dá trabalho". Para a equipe, era difícil sustentar essa intervenção arriscada, uma vez que não sabíamos o que encontraríamos em seu processo no fórum e, muito menos, que efeitos isso teria sobre a vida de Luka e como ele reagiria a isso.

Por fim, ele decidiu ir ao Fórum. Chegando lá, os funcionários tiveram grande dificuldade em encontrar o processo de Luka. Informaram que, uma vez alcançada a maioridade, o processo físico fica certo tempo no cartório e depois é enviado para arquivamento em uma central por um período e, depois, destruído. Foi desesperador cogitar que o único material capaz de fornecer a esse sujeito alguma pista sobre a história de sua família não existisse mais. Passadas algumas horas e muita insistência de nossa parte, o processo foi localizado.

Havia duas enormes pastas empoeiradas. Lemos juntos diversas partes do processo. Ali, descobrimos que a mãe de Luka havia sido presa por tráfico de drogas e, por isso, ele foi parar no abrigo. A essa, somavam-se outras informações dificeis sobre o contexto de vulnerabilidade que abarcava sua família de origem. Anotamos alguns nomes, endereços e telefones da época, na esperança de que pudéssemos localizar algum familiar.

Encontramos também registros sobre os processos de adoção e devolução que Luka havia vivenciado. Com evidente dor e coragem, ele leu o relato da educadoralmãe adotiva a seu respeito, justificando os motivos pelos quais não queria mais ficar com ele. Em um ponto da leitura, ele me interrompe e questiona: 'Então o problema é que eu brigava na escola? Mas todas as crianças têm alguma briga na escola. E ela disse também que eu era mal-educado e respondia para ela... Mas se ela era minha mãe adotiva, ela também tinha que me educar!'. Nessa passagem, ele parece despir-se do peso de ser aquele que não sabe ser um bom filho e, talvez pela primeira vez, se permite sentir raiva pela violência que viveu nesta relação com uma adulta que, por motivos que desconhecemos, estava impossibilitada de cuidar dele e o submeteu a grande sofrimento.

Em meio às incontáveis páginas, achamos um tesouro: ali estava escrito que sua mãe, ao sair da penitenciária, o havia visitado no abrigo por cinco vezes, até que se determinasse a proibição de sua visita e a destituição familiar. A partir deste ponto, nada mais importava para Luka: 'Ela não me abandonou! Ela foi me visitar no abrigo! Ela me queria!'. Uma virada se instaurava em sua constituição: ele havia sido desejado e amado pela mãe. 
No caminho de volta, no ônibus, eu mesma voltava impactada pela intensidade daquela experiência. Em meio a nosso silêncio, eu pensava em como ajudar Luka a dar um contorno a todo aquele redemoinho de informações e afetos. Surpreendendo-me, ele rompe o silêncio e pondera que a vida de sua mãe deveria mesmo ter sido muito difícil e que provavelmente ela tenha iniciado a participação no tráfico como uma tentativa desesperada por não encontrar outra alternativa para sustentar a si e aos filhos. Ele dá uma interpretação e um lugar afetivo para aquelas informações fragmentadas e busca, a partir de pedaços, construir um corpo.

Alguns dias depois, ele chegou ao escritório eufórico, dizendo que havia pesquisado a origem dos sobrenomes encontrados e que havia descoberto que ele era descendente de indígenas! Apontei que ele tinha, mesmo, alguns traços indígenas como o olho levemente puxado. Nesse momento, ele liga para um amigo, para contar que ele era índio e tinha até o olho puxado. 0 amigo pouco entendeu a relevância daquilo e logo desligou, irritado. Mas Luka e nós percebíamos o que estava em jogo.

Buscamos pelos endereços e telefones registrados no Fórum, porém, sem sucesso. Muito tempo havia se passado e as informações já estavam desatualizadas. Apesar de não termos conseguido produzir uma alteração na realidade concreta de Luka, algo importante em sua realidade psíquica mudou. Ele utilizava o encontro com elementos da história de sua família e sua infância para construir uma versão própria de sua história substituindo o buraco vazio que ocupava este lugar há anos.

Ele passou a ser o filho desejado, descendente de índios, que teve uma familia com muitas dificuldades, uma mãe guerreira que tentou resolver a situação e que não o abandonou, mas que o teve retirado por ocasião de sua detenção. Ele pôde construir para si um lugar de pertencimento neste mundo e, uma vez tendo este lugar de partida, conseguiu seguir caminhando.

Poucas semanas depois, ele nos ligou para dizer que não iria mais morar com a educadora, mas sim com uns amigos em uma pensão. Disse que tinha se cansado dessa história de abrigo, e havia saído meio fugido, mas que nós não nos preocupássemos, pois ele ficaria bem."

Apoiamo-nos na história relatada para abordar uma característica que compreendemos ser estruturante do trabalho do psicólogo neste contexto: o compromisso com a dimensão subjetiva e a sustentação do espaço para manifestação da singularidade, fazendo resistência ao rolo compressor homogeneizante de toda instituição.

Podemos verificar que diversos elementos biográficos das crianças e adolescentes em acolhimento institucional se repetem. Essas repetições constituem-se como indicadores de pertencimento dessas famílias a um determinado grupo social. Na maioria dos casos, as crianças acolhidas institucionalmente são negras, pertencentes a famílias pobres que residem nas periferias e carregam histórias de muitos rompimentos e acessos a direitos negados e outros tantos violados ao longo de gerações ${ }^{6}$ (Instituto de Pesquisa e Economia Aplicada, 2004; Fávero, Vitale e Baptista, 2008).

6 É necessário destacar que o fato de as familias de crianças acolhidas pertencerem em sua maioria a um mesmo grupo social nos aponta para a hipótese de que esta política pública se destina especificamente ao controle social de alguns grupos sociais determinados, e não que situações de desproteção e violência contra infância ocorrem apenas em famílias pobres. 
Tais elementos nos contam sobre os processos históricos e sociais de construção das situações em questão, processos estes que devem ser reconhecidos e tomados em análise para que possam ser alterados. Essa similaridade das trajetórias pode gerar um soterramento da singularidade - tanto na compreensão dos profissionais que acompanham as histórias quanto no olhar das próprias familias sobre si. A similaridade carrega consigo o risco de que se anulem as peculiaridades das histórias e das relações de cada família, além de sufocar a abertura para a maneira como cada um se posiciona frente a sua história, o que deseja e pode fazer dela.

Por mais que as crianças acolhidas vivam situações semelhantes quanto à vulnerabilidade, violação de direitos e grupo social ao qual pertencem, criando uma ilusão de unidade, consideramos imprescindível não interpretar a priori os comportamentos e as significações que cada sujeito atribui a sua história de vida e à própria situação de acolhimento institucional.

Ao não considerar uma identidade coincidente entre todos, nem um sentido fixo para as vivências, apostamos na força da criação de sentidos coletivos, que não apenas constroem uma interpretação para a história, mas, no mesmo ato, produzem história a partir das experiências e relações. Na cena com Luka, podemos acompanhar o caminho de certa reedição em que o fazer junto, a leitura dos relatórios, a ida ao Fórum, as conversas sobre o proibido, o encontro com outros adolescentes, permitiram a criação de outro sentido e de um giro no caminho.

Dessa forma, trabalhar pelo direito à história e à memória, incluindo-se suas partes mais difíceis e sofridas, possibilita ao sujeito a construção de uma narrativa e uma interpretação a respeito de si, sua família e do contexto sociopolítico em que está inserido, propondo, portanto, lidar com o sofrimento, não abafá-lo ou reprimi-lo. Frequentemente escutamos profissionais da assistência, do judiciário e, por consequência, as próprias crianças referindo-se ao período de acolhimento como uma nova vida, um recomeço, um virar a página, esquecer o passado e escrever uma nova história - ficam as perguntas: qual o custo subjetivo e político desse apagamento do passado? Ao silenciamento de quê situações e afetações ele se presta?

Acreditamos "que a instituição deva não só admitir toda a história de vida da criança como, principalmente, tolerá-la para engajar-se na construção ou no resgate de uma história ocultada, negada, rejeitada, pois se trata da história de sujeitos socialmente renegados" (Marin, 20 10, p.30). Quando a autora destaca a importância de estabelecer relações transparentes com a criança, nos alerta para os efeitos nocivos de uma relação ambígua, de afeto pseudomaterno, que visa apagar a triste história em que a crianças se encontra. Como direção ética de trabalho entendemos que:

[...] não se deve apenas preencher totalmente a criança, mas também permitir que ela questione sua origem, fale de seu abandono, entenda quem, no momento, está ocupando os lugares de proteção e apoio e, ao mesmo tempo, de limite e ordem e para onde deve seguir seu destino (qual o futuro possível colocado para ela). Estas são as possibilidades de lhe dar condições para ser um sujeito autônomo (Marin, 2010, p.61). 
Ancorados nessa compreensão, a tentativa de preencher a criança com aquilo que se considera faltoso a uma vida, tem relação direta com o lugar da família em nós e requer a necessidade da análise da implicação dos próprios profissionais, para que possamos deslocar nosso olhar do lugar social de referência absoluta, exclusiva e sacralizada que a familia tem em nossa sociedade para poder construir e habitar a função-acolhimento junto às crianças que acompanhamos no Saica e suas famílias.

Nesse ponto, chegamos a uma proposta muito familiar ao psicólogo, apesar de deslocada de seu enquadramento original: a oferta de espaço para a palavra e a aposta nos efeitos da fala. Falar sobre o que aconteceu, sobre onde dói, o que gosta, medos, lembranças, alegrias, indefinições, angústia, sobre o que se deseja, se espera, se sonha, sem a necessidade de um objetivo, funcionalidade ou direção predefinida para esta fala. A produção de fala enquanto prática de saúde, que põe a vida em questão e movimento.

As estratégias podem ser diversas e inventadas em cada contexto: grupos de fala de meninas, meninos, adolescentes, oficina de construção de histórias com crianças, assembleias ou qualquer outro dispositivo que se deseje e consiga criar. $\bigcirc$ indispensável é que esses espaços estejam garantidos entre as práticas na instituição - e o psicólogo seria um dos responsáveis por sustentar este eixo de trabalho. Não é necessário que o psicólogo esteja presente em todas as ações, mas uma possibilidade de ação é fomentá-las e dar sustentação para que outros também possam desenvolvê-las sabendo que contarão com um espaço de cuidado para si próprios, diante da angústia despertada pelo encontro com o sofrimento e questões das crianças e adolescentes. A atuação do psicólogo na instituição não se resume ao que pode ser produzido na relação direta com ele, corpo a corpo, mas no que ele impulsiona de movimento e diferença nas práticas institucionais.

Ainda a respeito da circulação da fala como estratégia para o trabalho, destacamos a importância de que sejam fomentados espaços de troca entre todos os trabalhadores da instituição, uma vez que lidarão com situações muito intensas e delicadas e mobilizarão o desamparo e as angústias de cada um dos profissionais envolvidos. Nesse sentido, pensamos a fala como recurso para certo distanciamento psíquico, que permita perceber afetos e implicações em jogo, podendo abrir caminho para uma leitura acerca das situações que nos sequestram e imobilizam ou nos fazem reagir automaticamente. A fala e a escuta como uma estratégia para a construção de sentido coletivo para o trabalho, radicalizando a compreensão de que o serviço não é dividido entre aqueles que pensam, planejam e decidem de um lado (técnicos) e aqueles que executam as tarefas de outro (educadores e auxiliares).

Portanto, garantia de dispositivos de fala e escuta para crianças e adolescentes, seus familiares e a própria equipe de trabalho, considerando a fala não apenas ou necessariamente como terapêutica, mas em sua dimensão de testemunho.

Testemunha também seria aquele que não vai embora, que consegue ouvir a narração insuportável do outro e que aceita que suas palavras levem adiante, como num revezamento, a história do outro: não por culpabilidade, ou por compaixão, mas porque somente a transmissão simbólica, assumida apesar e por causa do sofrimento 
indizível, somente essa retomada reflexiva do passado pode nos

ajudar a não repeti-lo infinitamente, mas ousar esboçar outra história, a inventar o presente. (Gagnebin, 2009, p.57)

\section{O COLETIVO, O SINGULAR, E O PSICÓLOGO COM ISSO?}

Em uma instituição de acolhimento, somos convocados a lidar com situações muito complexas e a tomar decisões difíceis e rápidas, o que pode gerar um alto nível de angústia ou, pelo avesso, apatia nos profissionais - afetos que vêm como expressão da complexidade e responsabilidade em jogo. O psicólogo apoia a equipe na construção da possibilidade de suportar essa angústia e o não-saber-o-que-fazer, compreendendo-os não como falhas ou faltas, mas como matéria-prima à lapidação de alternativas criativas e vivas para cada caso, mesmo em meio à pressão e ao enorme volume de trabalho. Trabalha, portanto, para que a dimensão paradoxal e imponderável da subjetividade esteja sempre presente, compondo a leitura das situações para tecer caminhos e decisões que representem o peso do sujeito, e não da instituição.

Uma vez que apontamos para uma atuação que dê sustentação à singularidade e faça resistência às ações massificantes, é necessário trazer a dimensão do desejo de cada criança e adolescente como uma das referências centrais para pensar as ações relacionadas à sua vida. Isso implica que a criança não seja apenas objeto do desejo dos adultos ou da Assistência Social, da ação de outrem que sempre sabe a priori o que é o bem, ou o melhor, pautando-se em interesses externos e referenciais generalizados, mas que possa ter seu desejo compondo o rol de elementos do processo de atenção e cuidado. No cenário atual, esta afirmação pode ser considerada uma obviedade do ponto de vista da compreensão dos profissionais e do tom dominante nos textos oficiais da legislação e das instituições. Contudo, as implicações na reorientação do trabalho e das práticas não são tão óbvias e traz uma complexidade para os processos de trabalho.

Orientados por essa ética, temos a responsabilidade de problematizar práticas bastante corriqueiras nas instituições de acolhimento, como propostas de passeios em que todos vão juntos para o mesmo lugar, decidido por algum membro da diretoria da organização, independentemente de idade, momento de vida, contexto cultural e interesses das crianças e adolescentes. Essa análise se estende também às diversas atividades cotidianas oferecidas no contraturno da escola, destacando a importância da participação de cada um na escolha da forma como deseja ocupar seu tempo livre, favorecendo o comprometimento, o interesse e a implicação das crianças e adolescentes com os mesmos. $\bigcirc$ que nos cabe, por exemplo, quando trabalhamos em um serviço administrado por uma organização evangélica, que leva as crianças ao culto todos os domingos, mas um dos adolescentes quer frequentar um terreiro de umbanda?

O mesmo se aplicaria com relação às decisões a respeito dos encontros com a família, sua frequência, atentando para as dificuldades e possibilidades que a criança identifica na relação com seus familiares e que caminhos ela consegue vislumbrar como possíveis, sendo protagonista dessa construção, e não apenas empurrada ou puxada de lá para cá de acordo com a avaliação exclusiva dos adultos (familiares e, principalmente, profissionais). 
Destacamos a importância da intencionalidade das ações praticadas, aliada à criação de estratégias para alcançar, ainda que parcialmente, os objetivos propostos, o que nos remete diretamente ao âmbito do posicionamento político frente ao trabalho. Com minha prática, o que busco fortalecer? Para onde caminho e o que pretendo? É imprescindível, para a atuação do psicólogo, ter condições de refletir, debater e se posicionar com relação a questões que permeiam transversalmente a própria existência deste campo.

Nesse sentido, uma suposta neutralidade asséptica do técnico é algo perverso, quando este, por exemplo, propõe atendimentos levando em conta exclusivamente questões psicológicas, quando enquadra meninos e famílias em diagnósticos aprisionantes, encaminha burocraticamente, sem construir um caminho para a efetivação deste encaminhamento, propõe protocolarmente algo que ele mesmo não acredita que irá funcionar, cumpre determinações como se não houvesse possibilidade de questionamento ou de construção de alternativas ou se esconde atrás dos famosos "protocolos".

A respeito do trabalho dos psicólogos, Mello e Patto (2008) afirmam que:

[...] sem a consciência da imensa responsabilidade dessas práticas, esses profissionais podem lesar direitos fundamentais das pessoas e, no limite, colaborar para a negação de seu direito à vida. Um psicólogo que não adquirir a capacidade de pensar o próprio pensamento da ciência que pratica, ou seja, de refletir sobre a dimensão epistemológica e ética do conhecimento que ela produz, certamente somará, insciente, com o preconceito delirante, a opressão, o genocídio e a tortura. (Mello \& Patto, 2008, p.594) 


\section{REFERÊNCIAS BIBLIOGRÁFICAS}

Altoé, S. (2010). A psicanálise pode ser de algum interesse no trabalho institucional com crianças e adolescentes? In S. Altoé (Org.). Sujeito do direito, sujeito do desejo: direito e psicanálise ( $3^{\mathrm{a}}$ ed.). Rio de Janeiro: Revinter.

Brasil. (1990). Estatuto da Criança e do Adolescente - ECA. Lei n 8069, de 13 de julho de 1990. Brasília, DF.

. (2005). Ministério do Desenvolvimento Social e Combate à Fome. Política Nacional de Assistência Social - PNAS/2004. Novembro de 2005. Brasilia, DF.

(2006a). Conselho Nacional dos Direitos da Criança e do Adolescente/ Conselho Nacional de Assistência Social. Plano Nacional de Promoção, Proteção e Defesa do Direito de Crianças e Adolescentes à Convivência Familiar e Comunitária. Brasília, DF.

. (2006b). Ministério do Desenvolvimento Social e Combate à Fome. Norma Operacional Básica de Recursos Humanos do SUAS - NOB-RH/SUAS. Dezembro de 2006. Brasília, DF.

(2009). Ministério do Desenvolvimento Social e Combate à Fome. Conselho Nacional dos Direitos da Criança e do Adolescente e Conselho Nacional de Assistência Social. Orientações Técnicas: Serviços de Acolhimento para Crianças e Adolescentes. Brasilia, DF.

. (20 I I). Resolução n 17, de 20 de junho de 20 I I. Conselho Nacional de Assistência Social - CNAS. Diário Oficial da União. República Federativa do Brasil. N | | 8, 2 I de junho de 20। I. Seção I. Brasillia, DF.

Fávero, E. T., Vitale, M. A. F., \& Baptista, M. V. (Orgs.). (2008). Famílias de crianças e adolescentes abrigados. São Paulo: Paulus.

Foucault, M. (2009). A ordem do discurso: aula inaugural no Collège de France, pronunciada em 2 de dezembro de 1970 (19a ed.). São Paulo: Loyola.

Gagnebin, J. M. (2009). Lembrar, escrever, esquecer. São Paulo: Editora 34.

Guattari, F. (1992). Da produção da subjetividade. In F. Guattari. Caosmose: um novo paradigma estético. Rio de Janeiro: Editora 34.

Instituto de Pesquisa e Economia Aplicada (IPEA). (2004). Levantamento nacional de abrigos para crianças e adolescentes da rede de serviços de ação continuada. Recuperado em 3 maio, 2017, de http://www.mpsp.mp.br/portal/page/ portal/infanciahome_c/acolhimento_institucional/Doutrina_abrigos/IPEA 
._Levantamento_Nacional_de_abrigos_para_Criancas_e_Adolescentes_da_Rede_ SAC.pdf.

Marin, I. S. K. (20 I0). Febem, família e identidade: o lugar do outro (3a ed.). São Paulo: Escuta.

Mello, S. L., \& Patto, M. H. S. (2008). Psicologia da violência ou violência da psicologia? Psicologia USP, 19(4), 59l-594.

Moreira, M. I. C., Bedran P. M., Carellos S. D., \& Passos A. P. C. P. (20|3). As famílias e as crianças acolhidas: histórias mal contadas. Psicologia em Revista, 19(1), 59-73.

Rizzini, I. (2008). O século perdido: raízes históricas das políticas públicas para a infância no Brasil (2a ed.). São Paulo: Cortez.

Rizzini, I., \& Pilotti, F. (Orgs.) (20 I I). A arte de governar crianças: a história das políticas sociais, da legislação e da assistência à infância no Brasil ( $3^{\mathrm{a}}$ ed.). São Paulo: Cortez.

Roudinesco, E., \& Plon, M. (1998). Dicionário de psicanálise. Rio de Janeiro: Jorge Zahar.

Vicentin, M. C. G. (20|6). Criançar o descriançável. In E. Lauridsen-Ribeiro \& C. B. Lykouropoulos (Orgs.). O Capsi e o desafio da Gestão em Rede (p.29-38). São Paulo: Hucitec. 